\title{
Atypical Unilateral Sacroiliitis Secondary to Mechanical Stress Injury
}

\author{
Tonine Younan-Farah ${ }^{1 *}$, Mohamed Zibawi ${ }^{1}$, Leila Abs ${ }^{1}$, Fouad Fayad ${ }^{2}$ \\ 1. Department of Radiology, Hotel-Dieu de France Hospital and Faculty of Medicine-Saint Joseph University, Beirut, Lebanon \\ 2. Department of Rheumatology, Hotel-Dieu de France Hospital and Faculty of Medicine-Saint Joseph University, Beirut, Lebanon \\ * Correspondence: Dr. Tonine Younan-Farah, Department of Radiology, Hotel Dieu de France Hospital, Saint Joseph University, Alfred \\ Naccache Street, Achrafieh, Beirut, P.O.Box 166830, Lebanon \\ $(-4$ tonine_younan@hotmail.com)
}

Radiology Case. 2020 Sep; 14(9):10-17 :: DOI: 10.3941/jrcr.v14i9.3582

\begin{abstract}
We report for the first time a case of atypical unilateral sacroiliitis secondary to mechanical stress injury. Unilateral sacroiliitis can be caused by a variety of etiologies. The first diagnosis to rule out is infection since it requires urgent treatment to avoid its serious consequences. Spondyloarthritis can be manifested by unilateral sacroiliitis in its early stage. Sacral fractures should always be looked for on the imaging modalities performed. In our case, no signs of infection or systemic disease were found. No fracture was seen on the imaging examinations and we had negative cultures on the computed tomography-guided biopsy realized. A history of mechanical stress was the only clue found suggesting the diagnosis of a probable stress related sacroiliitis. A thorough review of the literature will be provided stating the different causes of sacroiliitis described till now, with discussion of this new reported entity.
\end{abstract}

\section{CASE REPORT}

\section{CASE REPORT}

We report the case of a 26-year-old man who consulted in the rheumatology department for a right buttock pain that started one month earlier, $24 \mathrm{~h}$ after an unaccustomed stress while he was trying to pull a very heavy weight (a small boat) with intensive physical effort. The pain was continuous, invalidating and partially reduced using oral nonsteroidal antiinflammatory drugs (NSAIDs). It was irradiating to the posterior aspect of the thigh on the same side. The patient is an athlete and has no particular medical history.

He has no joint laxity and he was not suffering from pubic symphysis instability.
On physical examination, the patient presented a limping gait with severe pain on palpation and mobilization of the right sacroiliac joint. He had no fever, chills, mucocutaneous lesions, or diarrhea. No recent history of gastrointestinal or genitourinary infection. All the performed blood tests including CBC, ESR, CRP, HLA-B27, HLA-B5, PPD, Quantiferon, HBV, HCV, HIV, Brucella, Chlamydia, Syphilis, and Lyme disease serology were negative. Vitamin D, TSH and PTH levels were normal.

Magnetic resonance imaging (MRI) of the lumbar spine showed no particular findings. MRI of the sacroiliac joints (Figure 1), showed articular synovitis with small subchondral bone erosions at the anterior aspect of the right sacral surface, associated with slight subchondral bone edema and adjacent soft tissue swelling. Following these results, an infectious 
sacroiliitis was suspected and a computed tomography (CT)guided articular puncture was performed (Figure 2). The result of the bacterial culture test was negative. Gastroscopy revealed a hiatal hernia and ileo-colonoscopy was normal.

One month later, a CT scan of the pelvis and a new MR examination of the sacroiliac joints were performed (Figure 3). The CT scan showed the appearance of new several bone erosions at the anterior aspect of the right iliac surface, in addition to the presence of small bone sequestra in the joint (Figure 3a-b). The MRI revealed an enhancing bone edema at the articular surfaces especially at the iliac side, and increased erosions (Figure 3c-d-e-f). Based on the previous findings, a CT-guided bone biopsy of the right sacroiliac joint was performed (Figure 4). Histologic studies showed no specific findings. Routine bacterial as well as mycobacterium cultures came back negative.

The patient was ordered to keep rest and to avoid sports and intense physical activities.

This led to a pain intensity reduction of $70 \%$ after one month. Complete resolution of pain and disability was observed after a 3-month course of Diclofenac $\AA$ associated with physical therapy. He did not receive any antibiotics. The MRI examination performed 5 months after the onset of pain, (Figure 5a-b-c) showed a complete regression of bone edema and erosions at both articular surfaces, with appearance of a fatty signal in the adjacent bones, in addition to the resolution of the synovitis. Four years later, the MRI examination showed the same findings on the right side with normal left sacroiliac joint (Figure 5d-e-f). During these four years, the patient did not experience new flares of sacroiliac pain. The diagnosis of atypical unilateral sacroiliitis secondary to mechanical stress injury was made.

\section{DISCUSSION}

\section{Etiology \& Demographics:}

Sacroiliac (SI) region pain is a common clinical presentation and is often due to pathology in the SI joint, caused by a variety of etiologies (infectious, inflammatory, post-partum...).

However, a variety of other conditions can mimic true SI joint pain, the "non-SI pathology and mimickers". The most common of these conditions is spinal degenerative changes. The other conditions include piriformis syndrome, stress or insufficiency fractures, and neoplastic diseases. [1]

We report here a case of SI pain secondary to mechanical stress injury, showing an atypical aspect of sacroiliitis on imaging modalities.

\section{Clinical \& Imaging findings:}

Many patients with lower back or SI region pain will present to their primary care physician, specialist rheumatologist, or orthopedic surgeon. The initial challenge for the physician is to confirm origin of symptoms from the SI joints. Following a thorough clinical assessment and appropriate laboratory investigations, imaging forms the next major step and various imaging modalities are available to the clinician. Although conventional radiography is indicated in the initial evaluation of SI joints, it is often insensitive for the early changes of sacroiliitis, so other imaging modalities such as MRI, CT scan and isotope bone scintigraphy are often necessary. MRI is the preferred imaging modality due to the detection of early changes of sacroiliitis such as subchondral edema, and of non-SI pathology [1].

Our case was a 26-year-old male patient who presented a unilateral buttock pain $24 \mathrm{~h}$ after an unaccustomed stress while he was trying to pull a very heavy weight, with an aspect of unilateral sacroiliitis on the successive imaging modalities (CT scan and MRI), showing synovitis, bone edema, erosions and even bone sequestra. He had normal blood tests and negative CT-guided biopsy cultures. He had no personal nor familial history leading to spondylarthritis.

\section{Treatment \& Prognosis:}

Treatment and prognosis are related to the pathology involving the SI joints.

In our case, complete resolution of pain and disability were observed after a 3-month course of Diclofenac associated with physical therapy and rest. The patient did not receive any antibiotics. The last MRI performed 5 months and 4 years later showed a complete regression of the sacroiliitis pattern. Therefore, the diagnosis of unilateral sacroiliitis secondary to mechanical stress injury was made.

\section{Differential Diagnoses:}

\section{Infectious sacroiliitis:}

The most serious but uncommon differential diagnosis to be considered in this case is infectious sacroiliitis. It should be considered when there is unilateral sacroiliitis with erosive changes and bone marrow oedema within the SI joint, and soft tissue involvement or abscess formation [1,2,3].

In our case, MRI and CT scan showed unilateral sacroiliitis with synovitis, soft tissue involvement, bone edema and erosions of both articular surfaces and bone sequestra suggesting infectious etiology. This patient however had no fever neither systemic symptoms, he had normal blood tests, negative blood cultures and negative CT-guided biopsy cultures; allowing to rule out an infectious etiology.

\section{Spondyloarthritis:}

The most common differential diagnosis is unilateral inflammatory sacroiliitis as the first manifestation of spondyloarthritis. It is usually bilateral at later stages of the disease, but unilateral involvement has been noted in psoriatic arthritis, reactive arthritis, and in the early stages of ankylosing spondylitis [3]. Our patient had isolated unilateral buttock pain. There was no inflammatory back pain neither extra-articular manifestations that could be associated with spondyloarthritis. HLA B27 was negative and the response to NSAIDs was not spectacular. He had no muco-cutaneous lesions nor recent history of gastrointestinal or genitourinary infection. Furthermore, the clinical and radiological evolution 
at 4 years allowed us to eliminate the diagnosis of spondyloarthritis.

\section{Sacral stress fracture:}

Sacral stress fractures often manifest as low back pain, gluteal pain, coxalgia or sciatica. Stress fractures are either fatigue fractures or insufficiency fractures. MRI can detect early changes of sacral stress fractures with a sensitivity of nearly $100 \%$. MRI reveals a band of signal loss in T1 weighted images, and a band of increased signal intensity in the same area in fat-saturated T2 sequences, with surrounding bone marrow edema. Sacral stress fractures may present with vertical and/or horizontal components; vertical components may be unilateral or bilateral, but they nearly invariably involve the alar regions of the sacrum medial to the sacroiliac joints $[4,5,6,7]$. In our case, no typical sacral fracture was identified on the CT and MR images.

For differential diagnosis between sacroiliitis and stress fracture: in the former the lesions are seen on both articular surfaces with erosions, bone edema and synovitis, whereas the stress fractures are most commonly on the sacral side. In our case, we have the MRI aspect of a unilateral sacroiliitis, and that is why we performed a puncture and a biopsy to rule out an infectious etiology.

Our case was secondary to an intense effort, so most probably a mechanical stress injury was the primum movens of this atypical aspect of sacroiliitis. raising the possibility of micro fractures (not visible on MRI) of both articular surfaces with adjacent inflammatory changes.

Or we can probably extrapolate our case to the MRI changes of the sacroiliac joints during pregnancy and following labor, including bone marrow edema, capsulitis and enthesitis, reflecting most probably mechanical load, hormonal changes and dynamic instability [8,9]. While the vast majority of symptoms abate within weeks to months postpartum, $3.8 \%$ of women go to develop spondyloarthritis. Diffuse bone marrow edema and the presence of risk factors for spondyloarthritis are predictive of a chronic course [8].

We did not find any similar reported cases in the literature. Nonetheless, according to our case, a sacroiliitis pattern may occur secondary to mechanical stress injury and can be a self-limited condition. Therefore, in specific circumstances, this rare entity should figure out in the differential diagnosis of sacroiliitis.

\section{TEACHING POINT}

Mechanical stress injury should be considered as a cause of unilateral sacroiliitis when there is a history of excessive physical effort and after excluding other causes of sacroiliitis. Unilateral sacroiliitis induced by mechanical stress injury apparently has a good prognosis.

\section{REFERENCES}

1. Kok HK , Mumtaz A , O'Brien C, Kane D, Torreggiani WC , Delaney H. Imaging the Patient With Sacroiliac Pain. Can Assoc Radiol J. 2016 feb ;67(1):41-51. PMID: 26632100

2. Kang Y, Hong SH, Kim JY, et al. Unilateral Sacroiliitis: Differential Diagnosis Between Infectious Sacroiliitis and Spondyloarthritis Based on MRI Findings. Am J Roentgenol. 2015;205:1048-1055. PMID: 264996552

3. Brtalik D, Pariyadath M. A Case Report of Infectious Sacroiliitis in an Adult Presenting to the Emergency Department with Inability to Walk. J Emerg Med. 2017;52:e65-e68. PMID: 27866812

4. Memetoğlu OG, Ozkan FU, Boy NS, et al. Sacroiliitis or insufficiency fracture? Osteoporos Int. 2016;27:1265-1268. PMID: 26501559

5. Solmaz D, Soysal O, Ozaksoy D, et al. Bone marrow edema in the sacroiliac joint due to sacral stress fracture. J Clin Rheumatol. 2013;19:294-295. PMID: 23884188

6. Tamaki Y, Nagamachi A, Inoue $\mathrm{K}$, et al. Incidence and clinical features of sacral insufficiency fracture in the emergency department. Am J Emerg Med. 2017;35:1314-316. PMID: 28412162

7. Linstrom NJ, Heiserman JE, Kortman KE, et al. Anatomical and biomechanical analyses of the unique and consistent locations of sacral insufficiency fractures. Spine. 2009;34:309315. PMID: 19214089

8. Mahovic D, Laktasic-Zerjavic N, Tudor KI, et al. Pregnancy-related severe pelvic girdle pain caused by unilateral noninfectious sacroiliitis. A case report and literature review. Z Rheumatol. 2014;73:665-668. PMID: 24549922

9. Eshed I, Miloh-Raz H, Dulitzki M, et al. Peripartum changes of the sacroiliac joints on MRI: increasing mechanical load correlating with signs of edema and inflammation kindling spondyloarthropathy in the genetically prone. Clin Rheumatol. 2015;34:14191426. PMID: 26006255 


\section{FIGURES}

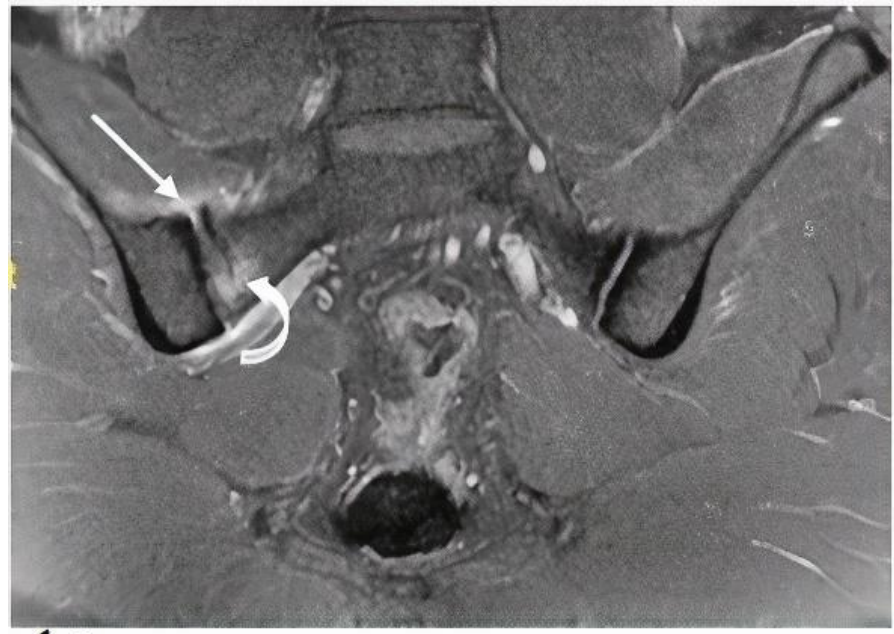

1.a

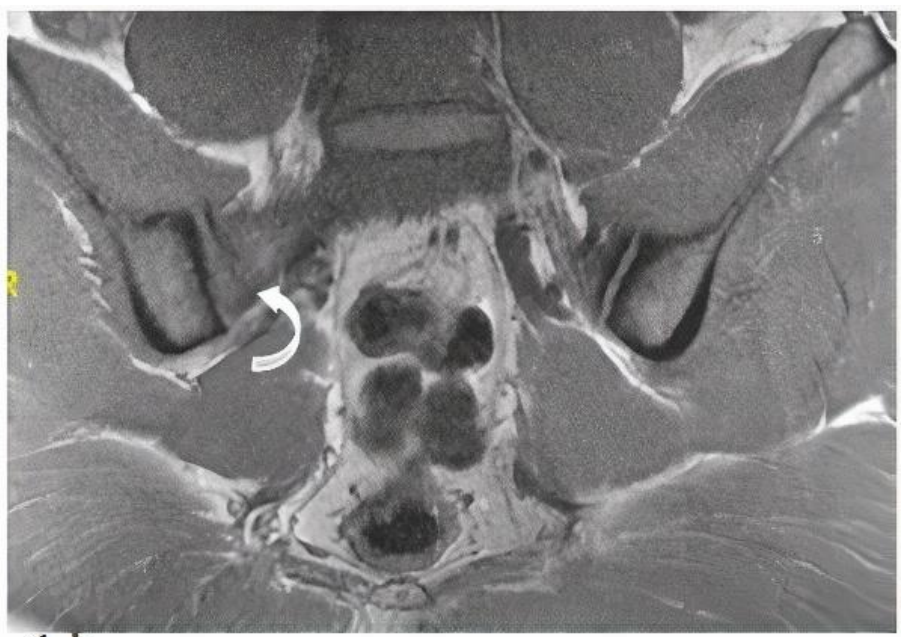

1.6

Figure 1: 26-year-old male with right sacroiliitis secondary to mechanical stress injury

a: Technique: coronal Proton Density Fat Sat weighted MR images. (3Tesla Magnet)

Findings: articular synovitis (white arrow) with small subchondral bone erosions at the anterior aspect of the right sacral surface associated with a slight bone edema (curved arrow).

b: Technique: coronal T1 weighted MR images. (3Tesla Magnet)

Findings: small subchondral bone erosions at the anterior aspect of the right sacral surface associated with a slight bone edema (curved arrow).
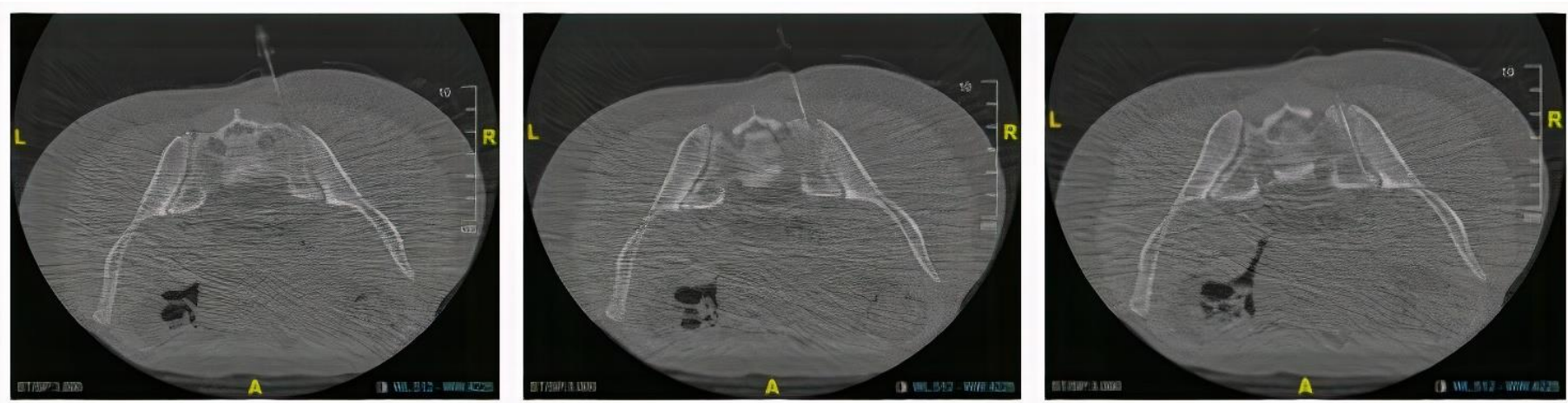

Figure 2: 26-year-old male with right sacroiliitis secondary to mechanical stress injury

Technique: axial CT scan image performed one week after the first MRI. (single-row detector scanner). 3mm slice thickness Findings: CT-guided fine needle puncture of the right sacroiliac joint 

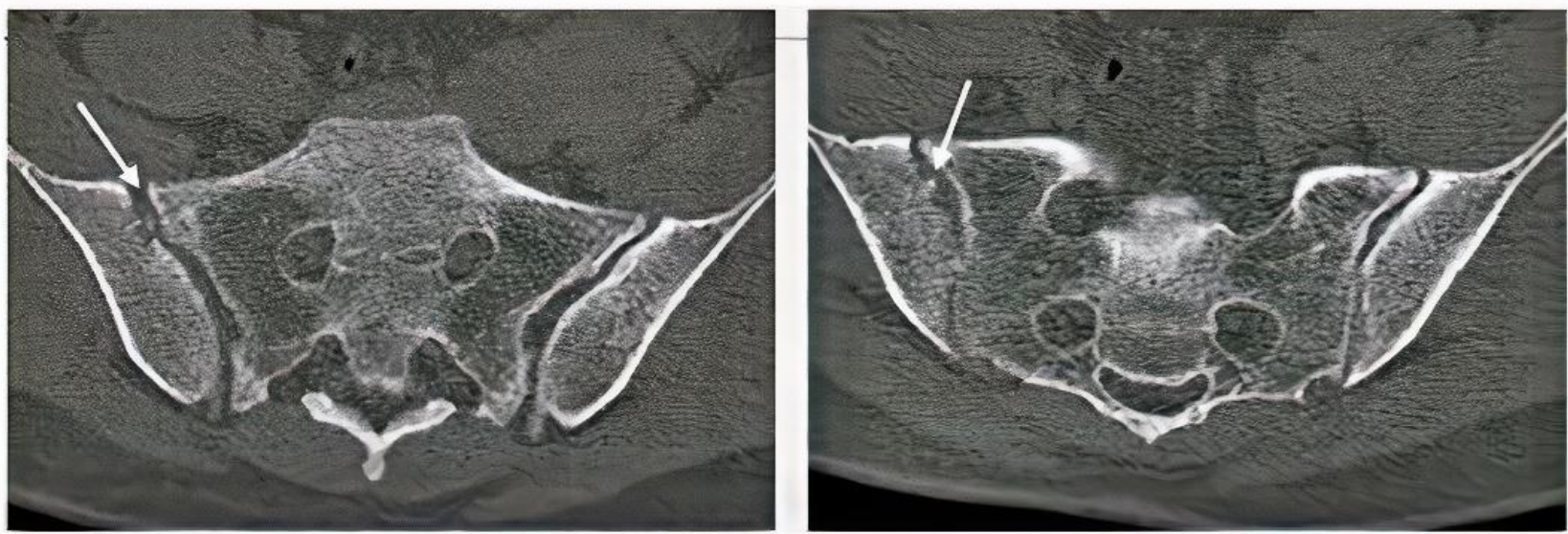

3.a

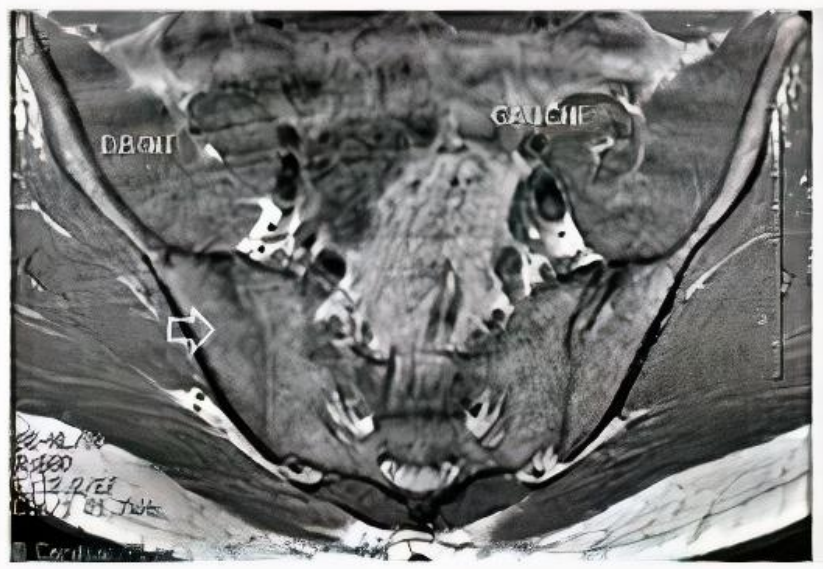

3.c

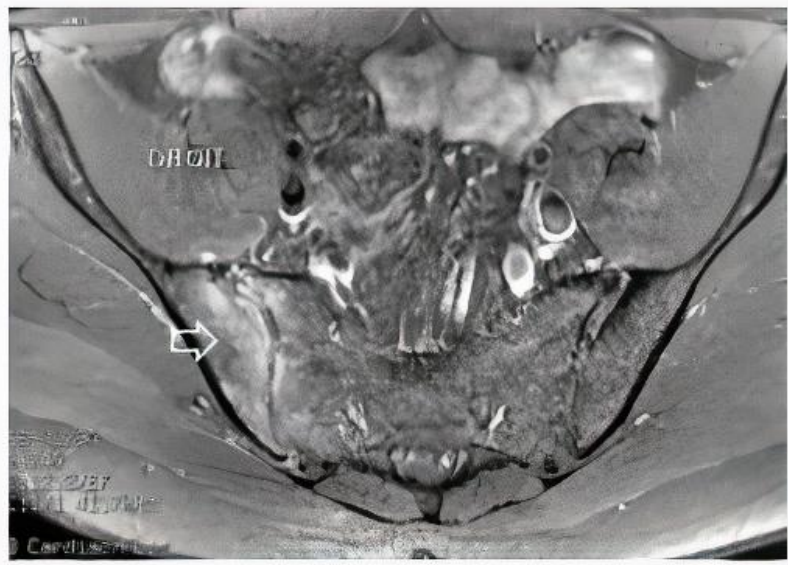

3.e 3.b

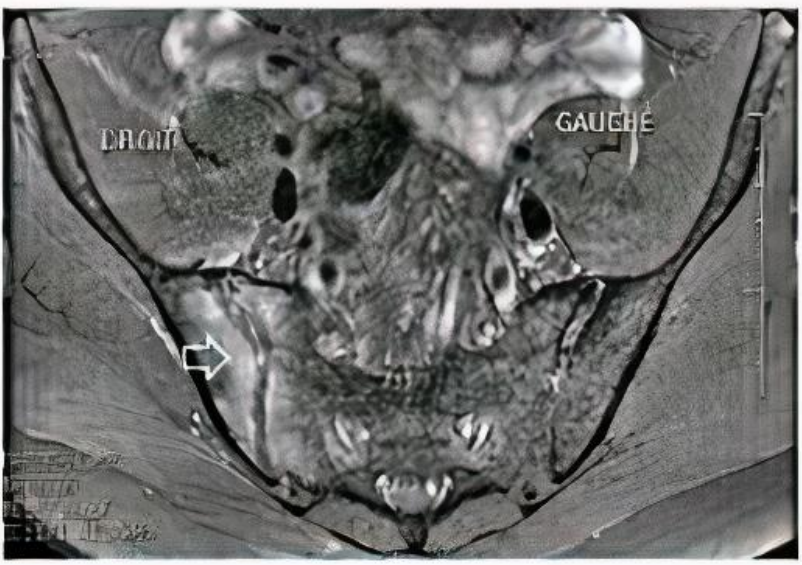

3.d

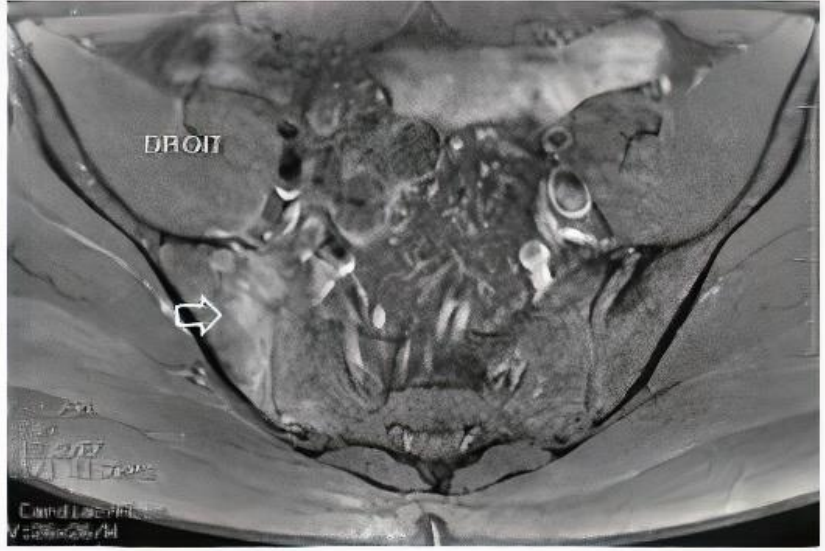

3.f

Figure 3: 26-year-old male with right sacroiliitis secondary to mechanical stress injury

a-b: Technique: axial CT scan performed one month after the first MRI. (64 detectors CT Scan). 0.6 mm slice thickness.

Findings: several bone erosions at the anterior aspect of the right iliac surface and small sequestra in the joint (white arrow) c: Technique: axial T1 weighted MR image performed one month after the first MRI. (3 Tesla Magnet)

Findings: increased bone edema and erosions at the articular surfaces especially at the iliac side (open arrow).

d: Technique: axial Proton Density Fat Sat weighted MR image performed one month after the first MRI. (3Tesla Magnet) Findings: increased bone edema and erosions at the articular surfaces especially at the iliac side (open arrow).

e-f: Technique: axial T1 Fat Sat + contrast weighted MR image performed one month after the first MRI. (3 Tesla Magnet) Findings: enhanced bone edema of the articular surfaces especially at the iliac side (open arrow). 


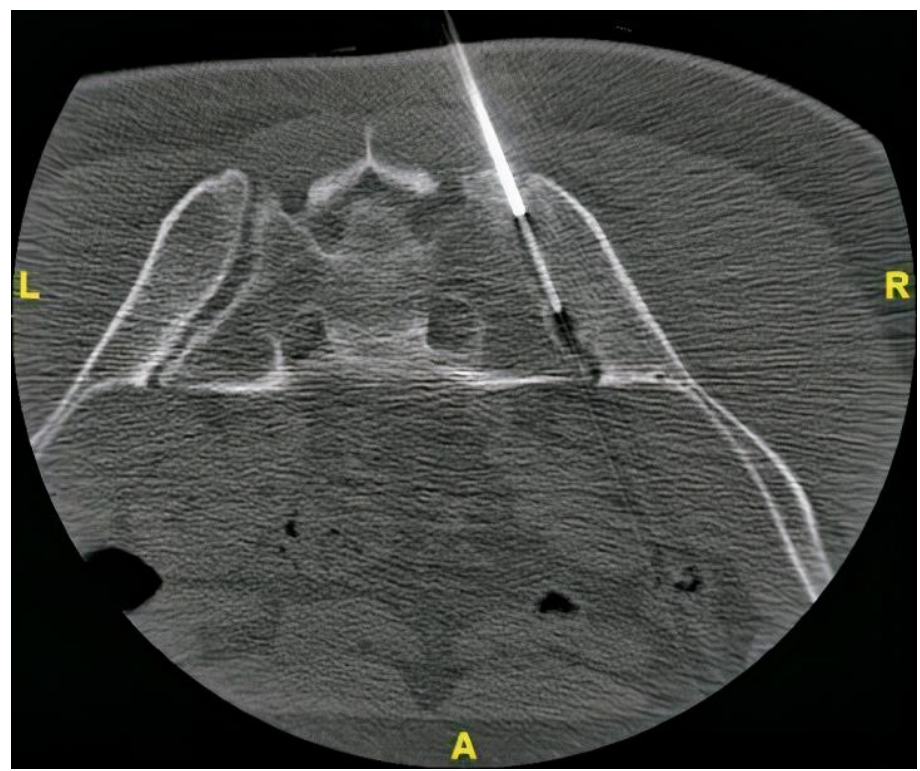

Figure 4 (left): 26-year-old male with right sacroiliitis secondary to mechanical stress injury

Technique: axial CT scan image performed one month after the first MRI. (64 detectors CT scan). 3mm slice thickness Findings: CT-guided biopsy of the right sacroiliac joint.
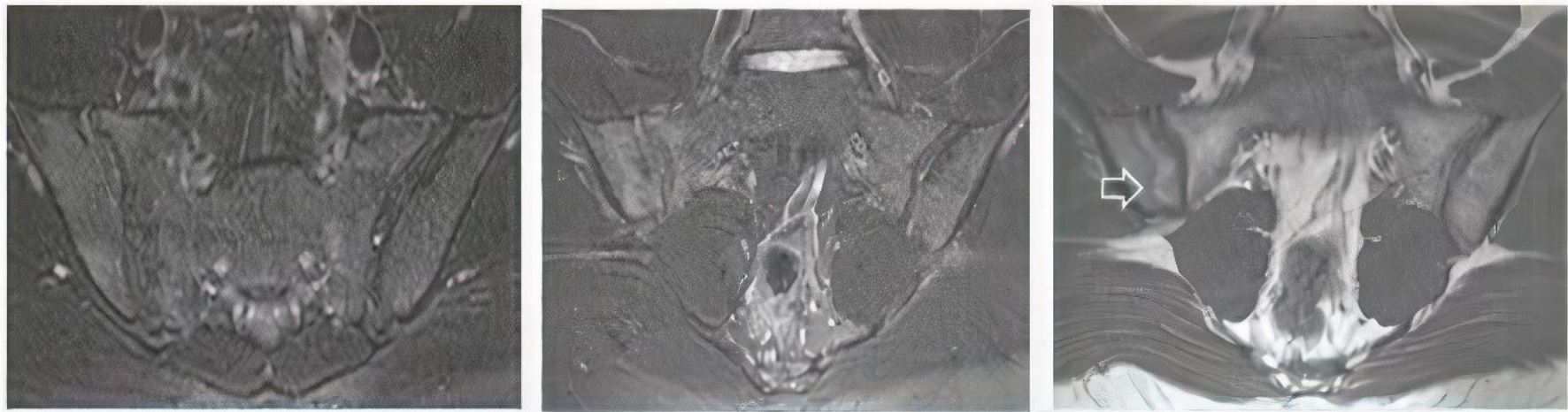

5.a

5.b

5.c
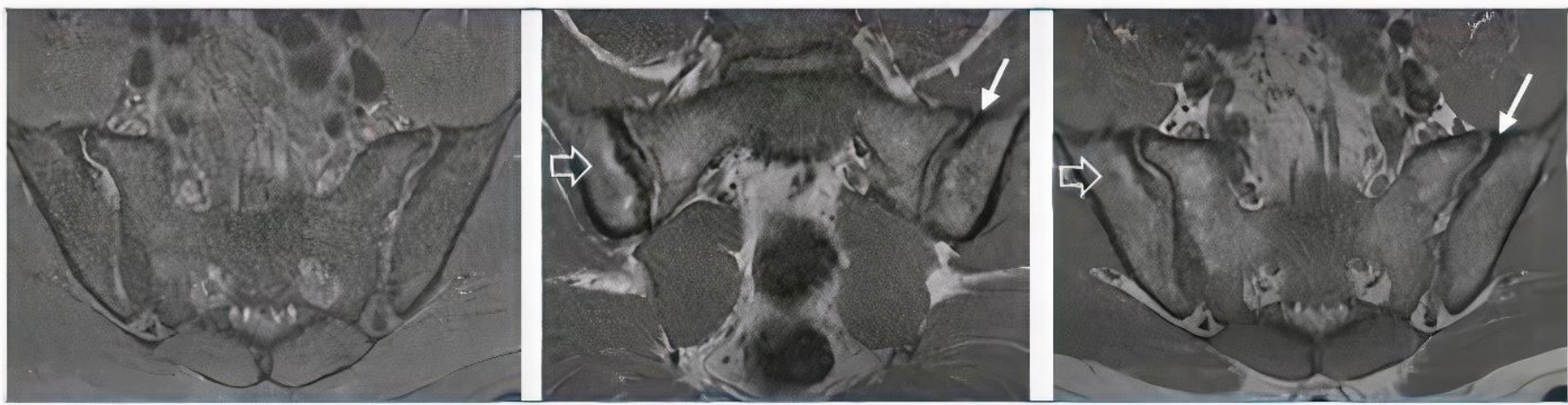

5.d

5.e

$5 . f$

Figure 5: 26-year-old male with right sacroiliitis secondary to mechanical stress injury

a-b: Technique: coronal Proton Density Fat Sat weighted MR images performed four months after the previous MRI. (3 Tesla Magnet)

Findings: complete regression of bone edema at both articular surfaces of the right sacroiliac joint, and resolution of the synovitis.

c: Technique: coronal T1 weighted MR image performed four months after the previous MRI

Findings: complete regression of bone edema and erosions at both articular surfaces of the right sacroiliac joint, with fatty replacement of bone marrow edema (open arrow)

d: Technique: Coronal Proton Density Fat Sat weighted MR image performed 4 years later. (3 Tesla magnet).

Findings: same findings as Fig.4.a-b.

e-f: Technique: Coronal T1 weighted MR images performed 4 years later

Findings: same findings as Fig.4.c with fatty replacement of bone marrow edema of both articular surfaces, in addition to mild osteosclerosis of the right iliac articular surface (open arrow) with a normal left sacroiliac joint (white arrow). 


\begin{tabular}{|c|c|c|c|c|}
\hline & X-Rays & CT & MRI & Bone scan \\
\hline $\begin{array}{l}\text { Unilateral } \\
\text { sacroiliitis } \\
\text { secondary to } \\
\text { mechanical } \\
\text { stress injury }\end{array}$ & Not available & $\begin{array}{l}\text { Unilateral } \\
\text { sacroiliitis, with } \\
\text { several bone } \\
\text { erosions at the } \\
\text { anterior iliac } \\
\text { surface, and small } \\
\text { bone sequestra in } \\
\text { the joint }\end{array}$ & $\begin{array}{l}\text { Unilateral sacroiliitis, with } \\
\text { articular synovitis, } \\
\text { subchondral erosions and } \\
\text { bone edema at the anterior } \\
\text { iliac surface, and slight } \\
\text { adjacent soft tissue } \\
\text { swelling, showing contrast } \\
\text { enhancement. }\end{array}$ & Not available \\
\hline $\begin{array}{l}\text { Infectious } \\
\text { sacroiliitis }\end{array}$ & $\begin{array}{l}\text {-Early stages: often normal } \\
\text {-Late stages: may show } \\
\text { unilateral } \\
\text { sacroiliitis, with sub- } \\
\text { chondral erosions } \\
\text { without sclerosis }\end{array}$ & $\begin{array}{l}\text {-Similar to x-rays } \\
\text { but CT is more } \\
\text { sensitive. } \\
\text {-May also show } \\
\text { intra-articular } \\
\text { bone sequestra } \\
\text { and/or adjacent soft } \\
\text { tissue collections. }\end{array}$ & $\begin{array}{l}\text { Unilateral sacroiliitis, with } \\
\text { synovitis and/or joint } \\
\text { effusion, erosive changes } \\
\text { and bone marrow edema. } \\
\text { Extra-capsular fluid } \\
\text { collections and } \\
\text { periarticular muscle edema } \\
\text { are more frequent in } \\
\text { infectious sacroiliitis. }\end{array}$ & $\begin{array}{l}\text { Increased tracer } \\
\text { uptake of the } \\
\text { affected SI joint. } \\
\text { May be normal if it } \\
\text { conducted early } \\
\text { after the onset of } \\
\text { symptoms }\end{array}$ \\
\hline Spondylarthritis & $\begin{array}{l}\text {-Usually bilateral sometimes } \\
\text { unilateral } \\
\text {-5 grades: } \\
\text { grade } 0 \text { : normal } \\
\text { grade 1: some blurring of the } \\
\text { joint margins. } \\
\text { grade 2: minimal sclerosis with } \\
\text { some erosions. } \\
\text { grade 3: definite sclerosis on } \\
\text { both sides of joint. Severe } \\
\text { erosions. Widening, narrowing, } \\
\text { and/or partial joint fusion. } \\
\text { grade } 4 \text { : complete ankylosis. } \\
\text {-bilateral changes of grade } 2 \text { or } \\
\text { higher, or unilateral changes of } \\
\text { grade } 3 \text { or higher are required to } \\
\text { diagnose sacroiliitis } \\
\text { radiographically. }\end{array}$ & $\begin{array}{l}\text { Similar to x-rays } \\
\text { but CT is more } \\
\text { sensitive. }\end{array}$ & $\begin{array}{l}\text {-Usually bilateral } \\
\text { sometimes unilateral. } \\
\text {-Active inflammatory } \\
\text { lesions: bone marrow } \\
\text { edema, synovitis, } \\
\text { enthesitis. T2 hypersignal } \\
\text { and contrast enhancement. } \\
\text {-Structural lesions: sub- } \\
\text { chondral sclerosis, } \\
\text { erosions, fat deposits and } \\
\text { ankylosis. Better visualized } \\
\text { on T1-weighted sequences. } \\
\text {-Bone marrow edema is } \\
\text { required to fulfill the } \\
\text { criterion of sacroiliitis on } \\
\text { MRI }\end{array}$ & $\begin{array}{l}\text { The sensitivity } \\
\text { (increased tracer } \\
\text { uptake) } \\
\text { of bone scan } \\
\text { is estimated at } \\
\text { about } 52 \% \text { in } \\
\text { patients without } \\
\text { radiographic } \\
\text { changes (grade 0) } \\
\text { and } 66 \% \text { in patients } \\
\text { with grade } 2 \text { and } 3 \text {. } \\
\text { It is even lower at } \\
\text { the ankylosis stage. }\end{array}$ \\
\hline $\begin{array}{l}\text { Sacral stress } \\
\text { fracture }\end{array}$ & $\begin{array}{l}\text {-Often normal } \\
\text {-may show vertical bands of } \\
\text { sclerosis and/or fracture lines in } \\
\text { the sacral ala }\end{array}$ & $\begin{array}{l}\text { Similar to X-rays } \\
\text { but CT is more } \\
\text { sensitive. }\end{array}$ & $\begin{array}{l}\text {-Sacral anomalies. } \\
\text {-Early bone marrow } \\
\text { edema: T2 hypersignal and } \\
\text { T1 hyposignal areas, } \\
\text { showing contrast } \\
\text { enhancement. } \\
\text {-Fracture lines: } \\
\text { hypointense lines within } \\
\text { the areas of edema. }\end{array}$ & $\begin{array}{l}\text { Bone scan has a } \\
\text { reported sensitivity } \\
\text { of } 96 \% \text { (increased } \\
\text { tracer uptake) }\end{array}$ \\
\hline
\end{tabular}

Table 1: Differential diagnosis table for atypical unilateral sacroiliitis secondary to mechanical stress injury. 


\begin{tabular}{|l|l|}
\hline Etiology & Traumatic \\
\hline Incidence & Unknown \\
\hline Gender ratio & Unknown \\
\hline Age predilection & Unknown \\
\hline Risk factors & Intensive physical effort \\
\hline Treatment & Rest, anti-inflammatory drugs and physical therapy \\
\hline Prognosis & Self-limited condition \\
\hline Findings on imaging & $\begin{array}{l}\text { X-Ray: not available. } \\
\text { MRI: right unilateral sacroiliitis with articular synovitis, subchondral erosions and bone edema at the } \\
\text { anterior iliac surface, and slight adjacent soft tissue swelling, showing contrast enhancement. } \\
\text { CT: right unilateral sacroiliitis with several bone erosions at the anterior iliac surface, and small bone } \\
\text { sequestra in the joint }\end{array}$ \\
\hline
\end{tabular}

Table 2: Summary table of atypical unilateral sacroiliitis secondary to mechanical stress injury.

\section{ABBREVIATIONS}

CT: computed tomography

MRI: magnetic resonance imaging

NSAID: non-steroidal anti-inflammatory drugs

SI: sacroiliac

\section{KEYWORDS}

Sacroiliitis; sacroiliac joint; buttock pain; stress injury; mechanical injury

\section{Online access}

This publication is online available at:

www.radiologycases.com/index.php/radiologycases/article/view/3582

\section{Peer discussion}

Discuss this manuscript in our protected discussion forum at: www.radiolopolis.com/forums/JRCR

\section{Interactivity}

This publication is available as an interactive article with scroll, window/level, magnify and more features.

Available online at www.RadiologyCases.com

\section{Published by EduRad}

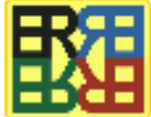

www.EduRad.org 